\title{
Psicose: história e análise descritivista de duas traduções para o
} português brasileiro/ Psycho: history and a descriptivist analysis of two

\author{
translations into Brazilian Portuguese
}

\author{
Carla Helena Lange* \\ Mirian Ruffini**
}

\begin{abstract}
RESUMO
Sob a perspectiva dos Estudos da Tradução, o presente artigo tem como objeto de estudo duas traduções da obra Psicose (1959), do escritor estadunidense Robert Bloch, para o português brasileiro, a saber: Psicose (1961), traduzida por Olívia Krähenbühl, e Psicose (2013), traduzida por Anabela Paiva. Sendo assim, o principal objetivo desta investigação é comparar as duas traduções, a fim de verificar a transposição do espaço e a ambientação insólita construídos por Robert Bloch nas respectivas traduções. Além disso, este trabalho também se preocupará em estudar o processo tradutório dos dois objetos de estudo e, para tal, será crucial o esquema para análise de traduções, proposto por José Lambert (2011), por meio dos Estudos Descritivos da Tradução. Por fim, com base nos estudos de Lanzetti et al. (2009), verificou-se a tradução de Krähenbühl (1961) pode ser classificada como uma tradução com a predominância de tendências domesticadoras, ao passo que a tradução de Paiva (2013) pode ser classificada como uma tradução com tendências principalmente estrangeirizadoras. Ambas as traduções parecem apresentar soluções para questões lexicais, sintáticas e culturais compatíveis com seus contextos de produção e suas respectivas configurações polissistemáticas.
\end{abstract}

PALAVRAS-CHAVE: Tradução; Psicose; Robert Bloch; Olívia Krähenbühl; Anabela Paiva.

\section{ABSTRACT}

From the perspective of Translation Studies, the present article aims to study two translations of Psycho (1959), by the American writer Robert Bloch, into Brazilian Portuguese, namely: Psycho (1961), translated by Olivia Krähenbühl, and Psycho (2013), translated by Anabela Paiva. Thus, the main objective of this investigation is to compare both translations, in order to verify the transposition of space and the uncommon setting constructed by Robert Bloch. In addition, this work will also be concerned with studying the translation process of both objects of study, and for this, the scheme for the analysis of translations, proposed by José Lambert (2011), by means of Descriptive Translation Studies, will be crucial. Finally, based on studies by Lanzetti et al. (2009), the translation by Krähenbühl (1961) could be classified as a translation with a predominance of domesticating tendencies, whereas the translation by Paiva (2013) could be estimated as a translation with mainly foreignizing tendencies. Both translations seem to offer solutions to lexical, syntactical, and cultural questions compatible with their production contexts and their polysystematic configurations.

KEYWORDS: Translation; Psycho; Robert Bloch; Olívia Krähenbühl; Anabela Paiva.

\footnotetext{
* Mestranda do Programa de Pós-graduação em Letras (PPGL) da Universidade Tecnológica Federal do Paraná - UTFPR, Campus Pato Branco, carllahelena@ hotmail.com

** Doutora em Estudos da Tradução, pela UFSC. Docente de Magistério Superior e do Programa de Pósgraduação em Letras (PPGL) na Universidade Tecnológica Federal do Paraná - UTFPR, Campus Pato Branco, mirianr@utfpr.edu.br
} 


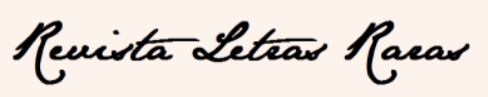

ISSN: 2317-2347 - v. 7, Edição Especial (2018).

\section{Primeiras considerações}

Publicado originalmente em 1959 pela editora Simon \& Schuster, Psicose é um dos mais de trinta romances do escritor estadunidense Robert Albert Bloch (1917 - 1994) que, além de escrever em ficção de prosa longa, também foi autor de diversos contos e roteiros para o cinema e a televisão. Seu mentor foi Howard Phillips Lovecraft, um dos mais importantes escritores de literatura fantástica, o qual incentivava o trabalho de Bloch que, na época, era um dos membros mais jovens do chamado Círculo de Lovecraft.

No entanto, ainda em 1959, Psicose ficou fora de circulação durante algum tempo nos Estados Unidos, haja vista que Alfred Hitchcock, diretor da adaptação cinematográfica homônima, comprou os direitos autorais do livro, bem como todos os exemplares das livrarias, pois não queria que ninguém soubesse o desfecho da história antes de assistir ao filme adaptado do romance de Bloch (REBELLO, 2013). Psicose, de Hitchcock, estreou nos cinemas em 1960 e, sem dúvida, contribuiu sobremaneira para a divulgação do romance de Bloch.

Em vista disso, o romance Psicose chegou ao Brasil pela primeira vez ainda em 1959, por meio da editora Record, com tradução de A. B. Pinheiro de Lemos. Contudo, essa edição está esgotada há anos e parece ter ficado esquecida, pois não se encontra referência à publicação em nenhum trabalho, artigo ou matéria jornalística. Não obstante a isso, pouco tempo depois, em 1961, surgiu a segunda edição e tradução brasileira de Psicose, desta vez pela editora Best Seller, com tradução realizada por Olívia Krähenbühl.

De acordo com Liv Brandão, repórter do jornal $O$ Globo, na década de 1960, Psicose foi um dos livros mais vendidos no Brasil ${ }^{1}$, porém, após essa década, a obra de Bloch ficou fora de circulação por quase cinquenta anos. Ainda assim, o romance mais famoso do pupilo de Lovecraft voltou a ser publicado em terras brasileiras no ano de 2013, com uma nova edição produzida pela DarkSide Books, com tradução de Anabela Paiva.

Isso posto, o presente trabalho tem como objeto de estudo duas traduções para o português brasileiro do romance Psicose: a de Olívia Krähenbühl, publicada

\footnotetext{
1 Disponível em: <https://oglobo.globo.com/cultura/psicose-livro-que-fisgou-hitchcock-relancado-nobrasil-9511396\#ixzz52x1LSqMT >. Acesso em: $01 \mathrm{dez} .2017$.
} 


\section{Pevista Leteas Racas}

ISSN: 2317-2347 - v. 7, Edição Especial (2018).

primeiramente em 1961, e a de Anabela Paiva, publicada em 2013. Frente a isso, o objetivo principal é comparar as duas traduções, a fim de verificar, nas traduções elencadas, as formas de transposição do espaço e da ambientação insólita construídos por Robert Bloch. Dentre os objetivos, destaca-se também a necessidade de conhecer a obra de Bloch, haja vista que o autor é pouco conhecido e estudado no Brasil. Ademais, este trabalho também se preocupa em observar o processo tradutório dos dois objetos de estudo e, para tal, utiliza-se o esquema para análise de traduções, proposto por José Lambert (2011). Para se referir ao texto Psicose (1959), de Robert Bloch, emprega-se a denominação "texto de partida" e, para as suas respectivas traduções, designa-se "texto de chegada".

Para essa finalidade, o presente trabalho está organizado nas quatro seções a seguir: "2 A Teoria dos Polissistemas, de Itamar Even-Zohar"; "3 A Literatura Fantástica na poética de Robert Bloch"; "4 As tradutoras: Olívia Krähenbühl e Anabela Paiva" e "5 Breve análise descritiva dos processos de tradução de Psicose".

\section{A Teoria dos Polissistemas, de Itamar Even-Zohar}

Com base no Formalismo Russo e no Funcionalismo Dinâmico, a Teoria dos Polissistemas foi concebida primeiramente a partir dos escritos de Itamar Even-Zohar, teórico israelense que participou da chamada Virada Cultural ou Escola da Manipulação nos Estudos da Tradução. Sua teoria apresenta conceitos amplos, de preocupação polissistemática, que não se restringem somente à literatura, posto que os textos literários agregam elementos de outros sistemas culturais. A amplitude da Teoria dos Polissistemas se deve ao fato de que:

A ideia de que os fenômenos semióticos, ou seja, os modelos de comunicação humana regidos por signos (tais como a cultura, a linguagem, a literatura, a sociedade), podem ser entendidos e estudados de modo mais adequado se os consideramos como sistemas, mais que como conglomerados de elementos díspares, converteu-se em uma das ideias diretrizes do nosso tempo na maior parte das ciências humanas e sociais. [...]

Assim sendo, a ideia de sistema tornou possível não só explicar adequadamente fenômenos "conhecidos", mas, também, desconhecidos (EVEN-ZOHAR, 2013, p. 1). 


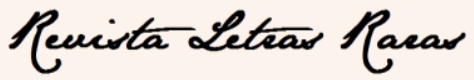

ISSN: 2317-2347 - v. 7, Edição Especial (2018).

Sendo assim, tem-se a noção de que as formas de comunicação humana - cultura, linguagem, literatura, sociedade, entre outras - podem ser melhor entendidas se organizadas como sistemas, uma vez que estão interligadas. Portanto, quando se fala de literatura, também se aborda uma linguagem com um código específico, de um determinado contex to social, histórico e cultural. Posto isso, nas palavras de Even-Zohar:

[...] são estas relações sistêmicas que determinam o status de certas unidades (propriedades, traços) em uma dada língua. A seleção de certo conjunto de traços para o consumo de certo grupo de status é, portanto, externa ao conjunto mesmo. De modo semelhante, o status de qualquer repertório literário está determinado pelas relações que existem no (poli)ssistema. [...]

Neste enfoque, a "literatura" não pode ser concebida nem como um conjunto de textos, uma junção de textos (o que parece um enfoque mais avançado), nem como um repertório. Os textos e os repertórios são apenas manifestações parciais da literatura, manifestações cujo comportamento não pode ser explicado por sua própria estrutura. Seu comportamento é explicável no nível do (poli)ssistema literário.

Sem dúvida, os textos são os produtos mais obviamente visíveis do sistema literário, ao menos em muitos períodos de sua história (EVENZOHAR, 2013, p. 10).

Sob essa perspectiva, a figura a seguir ilustra brevemente uma possibilidade de análise que representa os três polissistemas nos quais os objetos de estudo deste trabalho estão inseridos. O Polissistema $1(\mathrm{P} 1)$ está ligado à produção da primeira edição de Psicose, de Robert Bloch, em 1959, nos Estados Unidos. O Polissistema 2 (P2) apresenta a produção da tradução de Psicose, por Olívia Krähenbühl, em 1961, no Brasil. E, finalmente, o Polissistema 3 (P3) reflete a produção da tradução de Psicose, por Anabela Paiva, em 2013, no Brasil.

Figura 1: Representação das relações polissistemáticas de Psicose 


\section{Reuista Leteas Racas}

ISSN: 2317-2347 - v. 7, Edição Especial (2018).

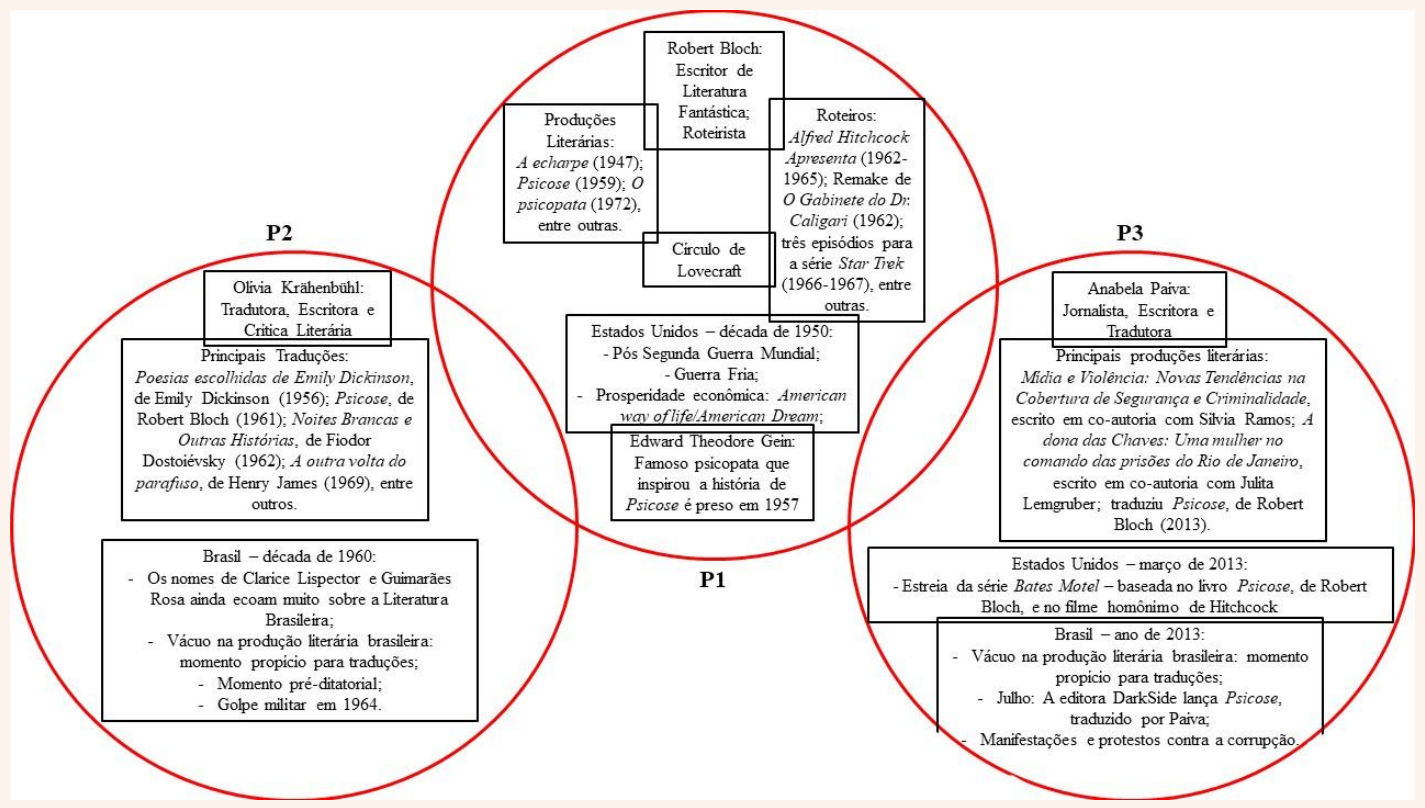

Em seguida, nas seções 3 e 4, com base na Fig. 1, exploram-se as relações entre o texto de partida, o romance Psicose, de Robert Bloch, em seu contexto de produção, e suas traduções brasileiras, de Olívia Krähenbühl e Anabela Paiva. As configurações polissistemáticas, simbolizadas pelo conteúdo de P1, P2 e P3, possuem o intuito de criar uma visualização panorâmica desse imbricamento e dar embasamento para a análise que será feita na seção 5. Aspectos históricos como a Segunda Guerra Mundial e governo Militar brasileiro contextualizam esta pesquisa, bem como elementos provindos do campo literário, como a influência de Lovecraft e as produções literárias das tradutoras, entre outros, constituem ricos subsídios para esta investigação.

\section{A Literatura Fantástica na poética de Robert Bloch}

Dentre as mais de trinta obras literárias de Robert Bloch, merecem destaque $A$ echarpe (1947), Psicose (1959) e O psicopata (1972). Para o cinema e televisão, Bloch foi o roteirista de dez episódios da série Alfred Hitchcock Apresenta (1962-1965), do remake de $O$ Gabinete do Dr. Caligari (1962) e de três episódios para a série Star Trek 


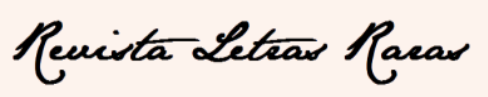

ISSN: 2317-2347 - v. 7, Edição Especial (2018).

(1966-1967). Em decorrência desses e de outros trabalhos, foi ganhador de diversos prêmios como o Hugo Award, Bram Stoker Award e World Fantasy Award².

De acordo com Ilana Casoy (2014), autora de Serial killers: louco ou cruel?, para escrever Psicose, Bloch teve como inspiração a história do serial killer Edward Theodore Gein (1906 - 1984). Nascido em La Crosse County - Wisconsin, norte dos Estados Unidos (vide P1 em: Fig. 1), Gein é considerado um dos piores psicopatas de todos os tempos, pois além de necrófilo e canibal, foi notório na década de 1950 por andar em sua propriedade travestido com roupas feitas de pele humana enquanto imitava sua mãe.

Estabelecendo uma possível relação com a história de Gein, a narrativa de Psicose se divide em duas tramas: a história de Norman Bates, um homem com quarenta anos de idade que vive e administra sozinho seu hotel de beira de estrada, o Bates Motel; e a vida de Mary Crane, uma secretária com quase trinta anos de idade que sonha em se casar com Sam Loomis, dono de uma loja de ferragens.

Entretanto, esses dois percursos se cruzam ainda na primeira parte da narrativa, quando Mary rouba quarenta mil dólares da imobiliária onde trabalhava e, após empreender fuga, hospeda-se no Bates Motel. Surpreendida pelo cair de uma noite chuvosa, Mary decide tomar sua refeição no hotel com Norman. A moça estranha o fato de que o rapaz e sua mãe morem sozinhos naquela casa distante. Aparentemente, a Mãe de Norman Bates era uma pessoa dominadora, que manifesta sua insatisfação ao perceber que o filho jantava com a hóspede.

Em seguida, durante o banho, Mary Crane é assassinada pela Sra. Bates, em cena que se tornou um ícone do cinema na adaptação Psicose (1960), dirigida por Hitchcock. Assim, o desaparecimento de Mary Crane desencadeia uma investigação, além de outras mortes, como o assassinato do detetive encarregado. Por fim, a polícia descobre que, além de se travestir e assumir a personalidade de Norma Bates, sua mãe que morrera há vinte anos, Norman a havia desenterrado e mantinha seu cadáver dentro de casa.

Dessa forma, o leitor notará uma ambientação cheia de suspense e horror em Psicose, principalmente na casa e no motel de Norman Bates: "The house was old, its frame siding gray and ugly here in the half-light of the coming storm" (BLOCH, 2010, p. 153). Sendo assim, a ambientação do espaço narrativo desenvolve um papel muito

\footnotetext{
${ }^{2}$ Informações disponíveis em: <http://www.darksidebooks.com.br/psicose/>. Acesso em: 05 out. 2017.
} 


\section{Reuista Leteas Racar}

ISSN: 2317-2347 - v. 7, Edição Especial (2018).

importante em Psicose, pois é por meio dela que os elementos do insólito corroboram para gerar o clima de suspense e horror.

Nesse sentido, é possível observar na familiaridade de Bloch com o gênero fantástico, clara influência de seu mentor, Lovecraft, o qual afirma que a atmosfera é o elemento mais importante para determinar sensações que geram uma ambientação insólita:

Evidentemente não podemos esperar que todas as histórias fantásticas se conformem à perfeição com algum modelo teórico. As mentes criativas são desiguais, e o melhor dos tecidos tem seus pontos frouxos. Ademais, boa parte da obra fantástica seleta é inconsciente, aparecendo em fragmentos memoráveis espalhados por material cujo efeito geral pode ser de molde muito diferente. Atmosfera é a coisa mais importante, pois o critério final de autenticidade não é a harmonização de um enredo, mas a criação de uma determinada sensação (LOVECRAFT, 2007, p. 17, grifos nossos).

Sob o mesmo ponto de vista, o mestre das narrativas de terror e mistério que influenciou muito H. P. Lovecraft, Edgar Allan Poe, ao fazer um estudo teórico acerca de "O Corvo" em 1846 (vide "A filosofia da composição"), defende que quanto mais fechado é o espaço, mais forte será a ambientação do horror:

O próximo ponto a ser considerado foi o modo de reunir o enamorado com o corvo - e a primeira escolha a ser feita dizia respeito ao lugar onde se encontrariam. A sugestão mais natural seria em uma floresta ou em um campo, mas sempre me pareceu que a restrição de um espaço fechado era absolutamente necessária para criar o efeito de um incidente isolado, como uma moldura em um quadro. Possui o incontestável dom moral de manter a atenção concentrada e, é claro, não deve ser confundida com uma mera unidade local (POE, 2017, p. 349-350, grifos do autor).

Em vista disso, nota-se a preocupação de Robert Bloch em desenvolver as cenas de horror nos ambientes mais fechados da casa e do motel como, por exemplo, o assassinato do detetive Arbogast, que acontece no vestíbulo da casa de Norman, e o encontro de Mary com Norma, que se passa no banheiro de um quarto do motel, conforme pode ser observado a seguir:

The roar was deafening, and the room was beginning to steam up. That's why she didn't hear the door open, or note the sound of footsteps. And at first, when the shower curtains parted, the steam obscured the face. 


\section{Reuista Leteas Racar}

ISSN: 2317-2347 - v. 7, Edição Especial (2018).

Then she did see it there - just a face, peering through the curtains, hanging in midair like a mask. A head-scarf concealed the hair and the glassy eyes stared inhumanly, but it wasn't a mask, it couldn't be. The skin had been powdered dead-white and two hectic spots of rouge centered on the cheekbones. It wasn't a mask. It was the face of a crazy old woman.

Mary started to scream, and then the curtains parted further and a hand appeared, holding a butcher's knife. It was the knife that, a moment later, cut off her scream.

And her head (BLOCH, 2010, p. 41, grifos nossos) ${ }^{3}$.

Conforme demonstra a citação, o ambiente fechado do banheiro, a banheira fechada com uma cortina e o vapor do chuveiro sugerem uma sensação de confinamento que desencadeia o medo de Mary. Por fim, Lovecraft ressalta que são os toques atmosféricos, isto é, a ambientação da história, a composição dos cenários, juntamente com a habilidade do escritor em trabalhar com esses elementos, que produzem a sensação de horror e sobrenatural:

Podemos dizer, generalizando, que uma história fantástica cuja intenção seja ensinar ou produzir um efeito social, ou uma em que os horrores são explicados no final por meios naturais, não é uma genuína história de medo cósmico; mas persiste o fato de que essas narrativas muitas vezes possuem, em seções isoladas, toques atmosféricos que preenchem todas as condições da verdadeira literatura de horror sobrenatural. Portanto, devemos julgar uma história fantástica, não pela intenção do autor ou pela simples mecânica do enredo, mas pelo nível emocional que ela atinge em seu ponto menos banal. Se as sensações apropriadas forem provocadas, esse 'ponto alto' deve ser admitido, por seus próprios méritos, como literatura fantástica, pouco importando quão prosaicamente ele seja degradado na sequência. O único teste do realmente fantástico é apenas este: se ele provoca ou não no leitor um profundo senso de pavor e o contato com potências e esferas desconhecidas; [...] (LOVECRAFT, 2007, p. 17-18).

Mediante o exposto, as próximas seções farão um estudo comparado das duas traduções escolhidas de Psicose, a fim de verificar a transposição, nas traduções

\footnotetext{
${ }^{3}$ Não podia ouvir nada além do barulho da água, e o banheiro começou a se encher de vapor.

Foi por isso que não percebeu a porta abrir, nem o som de passos. Logo que as cortinas do chuveiro se abriram, o vapor obscureceu o rosto.

Então ela viu - um rosto, espiando entre as cortinas, flutuando como uma máscara. Um lenço escondia os cabelos e os olhos vidrados a observavam, inumanos. Mas não era uma máscara, não podia ser. Uma camada de pó dava à pele uma brancura de cadáver; havia duas manchas de ruge nas maçãs do rosto. Não era uma máscara. Era o rosto de uma velha louca.

Mary começou a gritar. A cortina se abriu mais e uma mão apareceu, empunhando uma faca de açougueiro. E foi a faca que, no momento seguinte, cortou o seu grito.

E a sua cabeça (BLOCH, 2013, p. 55, grifo do autor).
} 


\section{Revista Leteas Racar}

ISSN: 2317-2347 - v. 7, Edição Especial (2018).

elencadas, da configuração do clima insólito presente na ambientação dos espaços da casa de Norman.

\section{As tradutoras: Olívia Krähenbühl e Anabela Paiva}

Olívia Krähenbühl (1900 - 1973) foi uma renomada tradutora e crítica literária brasileira que, além de Psicose ( $1^{\mathrm{a}}$ edição publicada em 1961 e $2^{\mathrm{a}}$ edição publicada em 1964, pela editora Best Seller), também é conhecida por suas outras traduções de clássicos da literatura, a saber: Poesias escolhidas de Emily Dickinson, de Emily Dickinson (1956, Saraiva), Noites Brancas e Outras Histórias, de Fiodor Dostoiévsky (1962, José Olympio) A outra volta do parafuso, de Henry James (1969, Ediouro), entre outras.

Em vista da impossibilidade de realizar uma entrevista com Krähenbühl, vale destacar um artigo publicado pela tradutora no jornal Correio da manhã, do Rio de Janeiro, em 3 de setembro de 1944, intitulado "Duplo aspecto da tradução". Neste artigo, Krähenbühl fala do trabalho tradutório, apresenta e comenta a profissão de escritor e tradutor e destaca a importância de o tradutor também ser um escritor:

Não andam muito longe da verdade aqueles que afirmam ser uma boa tradução tarefa mais difícil do que a feitura de uma obra original. Porque, argumentam, para bem escrever uma obra original, basta um certo domínio da língua, desde que o escritor tenha alguma coisa a dizer. Mas, para levar a cabo uma tradução bem-feita, é mister achar-se o tradutor na posse de uma espécie de alma dupla, além de conhecer, com a máxima perfeição, o vernáculo e a língua a traduzir. E é nesse duplo aspecto - de obra de ciência forrada de obra de arte - que reside a maior dificuldade para uma boa tradução.

$[\ldots]$

Afirma, entre nós, um editor inteligente (e os há, sem sombra de dúvida), existir um tradutor para cada obra a ser traduzida; um tradutor cujo temperamento por tal forma se afine com a obra original, ao ponto de, traduzindo-a, fazer da mesma uma verdadeira recriação.

[...]

Existe, ainda, o critério oposto: o de se confiarem traduções ao tradutor que não é escritor, ao tradutor tout court. $\mathrm{E}$ o resultado nos parece igualmente desastroso. Porque aí, se lucra a tradução enquanto obra de ciência, deixa, contudo, muito a desejar em seu aspecto de obra de arte. Ora, uma língua é, antes de tudo: a expressão natural do pensamento, não do sentimento, e as palavras são antes de símbolos de ideias, não de emoção. Logo, para transmitir o sentimento, faz-se preciso atentar não 


\section{Revista Leteas Racar}

ISSN: 2317-2347 - v. 7, Edição Especial (2018).

apenas nas palavras em si, mas também no seu arranjo, sua melodia, suas associações e as mil e uma maneiras pelas quais indiretamente elas sugerem e comunicam a emoção prendida por aqueles que as escreveram.

[...]

Logo, se um prejudica a tradução enquanto obra de ciência, outro igualmente a prejudica em seu aspecto de obra de arte. $O$ ideal, pois, seria reunirem-se escritor e tradutor numa mesma e só pessoa inseparável [...] (KRÄHENBÜHL, 1944, p. 1-4, grifos nossos).

Evidentemente, o polissistema cultural e literário brasileiro (representado como P2 em: Fig. 1), em que a tradução de Krähenbühl se insere, deve ser levado em consideração. Entretanto, a crítica da tradutora se aplica até os dias atuais, posto que a tradução linguística é um trabalho complexo, pois envolve muito mais do que uma mera troca de códigos. A tradução requer, de certa forma, que o tradutor esteja familiarizado com o polissistema cultural fonte e o de chegada.

Frente a isso e tendo em mente o polissistema cultural e literário do Brasil de 1960 (P2 em: Fig. 1), pode-se dizer que Krähenbühl traduziu Psicose sob uma perspectiva da época, incorporando uma linguagem condizente ao período em que estava inserida e, também, ao seu estilo de escrever, conforme pode ser observado no trecho do artigo "Duplo aspecto da tradução".

Com efeito, o contexto cultural e literário (P3 em: Fig. 1) em que Anabela Paiva atua é outro, devido à lacuna temporal entre as duas traduções aqui estudadas. Em entrevista para as autoras deste trabalho (vide Apêndice A), a jornalista conta que mantém contato com a língua inglesa desde a época em que viveu nos Estados Unidos, de 1989 a 1992, onde trabalhou como correspondente da Veja e Jornal do Brasil. Apesar de ter escrito dois livros em coautoria, Mídia e Violência: Novas Tendências na Cobertura de Segurança e Criminalidade, com Silvia Ramos, e A dona das Chaves: Uma mulher no comando das prisões do Rio de Janeiro, com Julita Lemgruber, sua experiência com tradução, até o momento, limita-se a Psicose (Lançado em 2013 pela DarkSide Books, em duas edições: Classic Edition e Limited Edition). No que tange ao trabalho do tradutor em relação às obras literárias, Paiva comenta o seguinte:

O trabalho do tradutor, sem dúvida, é quase o de um coautor da obra, especialmente em gêneros como a poesia. Quem traduz precisa encarar o trabalho com uma mistura de coragem e cuidado. Coragem, para, se necessário, fazer escolhas estilísticas de modo que o resultado da tradução seja fiel ao estilo e às intenções do original, e não apenas uma 


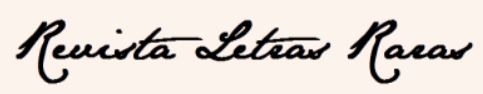

ISSN: 2317-2347 - v. 7, Edição Especial (2018).

tradução literal. Ao mesmo tempo, cautela, para jamais ultrapassar este simples objetivo - o que seria trair a obra literária (PAIVA, 2017, s/p).

Por esse ângulo, nota-se que a fala de Paiva vai ao encontro dos postulados de André Lefevere (2007) presentes em seu livro Tradução, reescrita e manipulação da fama literária, dado que, para ele, a tradução também funciona como uma reescritura, sendo uma maneira de manter viva uma obra. Consequentemente, destaca-se a importância do tradutor, pois, mais do que um trabalho de decodificação, ele reescreve, adaptada e projeta a imagem de um autor ou de determinada obra em um novo polissistema literário.

Em suma, os relatos das tradutoras, na forma de artigo, no caso de Krähenbühl, e da entrevista, realizada com Paiva, revelam suas crenças tradutórias que provavelmente norteiam seus trabalhos com a tradução literária e podem informar ao pesquisador a respeito dos seus objetos de estudo. Com a finalização desta etapa, constrói-se a próxima seção deste artigo, que propõe breve análise das duas traduções de Psicose.

\section{Breve análise descritiva dos processos de tradução de Psicose}

Com base na perspectiva polissistemática de Itamar Even-Zohar (2013) e no foco descritivista dos Estudos da Tradução propostos por Gideon Toury (2012), esta seção tem por finalidade fazer breve análise das duas traduções escolhidas de Psicose. Para isso, a partir daqui, levando em consideração a ordem cronológica de publicação das obras, ao se referir a tradução de Krähenbühl, adota-se a abreviação T1, e para a tradução de Paiva, $\mathrm{T} 2$.

A partir da aplicação de "Um esquema sintetizado para a descrição de tradução", elaborado por Lambert (2011), verificou-se a possibilidade de fazer um estudo descritivo das traduções, dividindo-se em quatro parâmetros: 1. Dados preliminares, 2. Macronível, 3. Micronível e 4. Contexto sistêmico. Na análise do macronível, segundo o autor, é possível verificar a organização e disposição de um livro, ao passo que o micronível está relacionado às mudanças internas das palavras. Por fim, o contexto sistêmico pode estabelecer uma relação entre os sistemas das traduções analisadas com outros sistemas culturais, de especial aplicação para esta análise. 


\section{Revista Leteas Racar}

ISSN: 2317-2347 - v. 7, Edição Especial (2018).

No caso da T1, em relação aos dados preliminares, é possível identificar na capa do livro, além do título e o nome do autor, a frase "Não leia à noite este livro, mormente se estiver só...”, o que indica, mesmo que indiretamente, o gênero do romance, suspense. Entretanto, o nome da tradutora, Olívia Krähenbühl, somente é mencionado na páginatítulo. Interessante destacar que a fonte de letras para palavra "Psicose", presente na capa e na página-título, é a mesma que foi utilizada na primeira edição de Robert Bloch, em 1959, indicando esta proximidade entre as publicações. Por fim, pode-se dizer que a T1 é uma tradução completa, porém, não faz uso de nenhum metatexto como, por exemplo, notas de rodapé.

No que tange aos dados preliminares, a T2 contém duas edições com capas diferentes: a "Limited Edition", uma edição de luxo que apresenta uma capa muito semelhante àquela da primeira edição de 1959 de Robert Bloch, além de um caderno especial com fotos da adaptação cinematográfica de Hitchcock; e a "Classic Edition", uma edição na versão brochura, com capa inspirada na adaptação de 1960 de Psicose para o cinema, porquanto além da frase "O romance que originou o clássico de Hitchcock", presente na capa, há também o desenho de sangue que escorre para um ralo, cena que remete ao filme citado. Ambas as edições utilizam a mesma fonte de letra da primeira edição de 1959, somente diferindo no design das capas, no caderno de imagens (versão de luxo) e na frase presente na capa da edição de brochura. As edições da T2 não fazem nenhuma menção ao gênero do livro, bem como só mencionam o nome da tradutora, Anabela Paiva, na página-título. Por isso, apresenta igualmente uma tradução completa e com alguns metatextos como, por exemplo, uma nota de rodapé na página 223 , na qual esclarece de forma sucinta a respeito de Ed Gein.

No macronível, tanto a T1 quanto a T2 apresentam divisão em capítulos da mesma maneira adotada por Bloch. Enquanto a T1 mantém os dezessete capítulos intitulados apenas com numerais, a T2 intitula os capítulos com as primeiras palavras destes, a saber: Capítulo 1: "Norman Bates ouviu o som e estremeceu"; Capítulo 2: "Mary levou vários minutos para notar a chuva"; Capítulo 3: "Procurando um quarto?"; Capítulo 4: "No minuto em que entrou no escritório..."; Capítulo 5: "Norman trancou a porta e subiu a colina até a casa"; Capítulo 6: "Pontualmente às seis da tarde..."; Capítulo 7: “O Stetson cinzento estava agora sobre a mesa..."; Capítulo 8: “O amanhã se tornara hoje...”; Capítulo 9: “Tarde de sábado...”; Capítulo 10: “Norman sorriu para o homem 


\section{Reuista Leteas Racar}

ISSN: 2317-2347 - v. 7, Edição Especial (2018).

idoso..."; Capítulo 11: "Sam e Lila, sentados no quarto dos fundos...”; Capítulo 12: "Sam e Lila almoçam no hotel."; Capítulo 13: "Norman sabia que viriam..."; Capítulo 14: "Por um momento, Sam teve a esperança..."; Capítulo 15: "Lila subiu os degraus e chegou à varanda bem na hora..."; Capítulo 16: "A retirada dos carros e dos corpos do pântano...”; Capítulo 17: “O verdadeiro fim veio calmamente.”. A estratégia de intitular os capítulos utilizada pela $\mathrm{T} 2$, pode ser entendida como uma maneira de prender o leitor ao livro, haja vista que os títulos prenunciam o que acontecerá no capítulo seguinte.

No que diz respeito ao micronível da tradução, isto é, as modificações gráficas, fônicas, sintáticas, lexicais, entre outras, pode-se dizer que T1 e T2 possuem suas peculiaridades. Portanto, a partir das tabelas dispostas abaixo, será possível fazer uma breve análise do micronível de ambas traduções, além de verificar se T1 e T2 conseguiram manter a ambientação insólita proposta por Bloch, a qual se dá por meio das escolhas lexicais, conforme observado na terceira seção do presente artigo.

Considerando-se a importância do espaço narrativo, a tabela a seguir descreve o momento em que Lila, irmã de Mary, decide vasculhar a casa de Norman e, ao descrever pela primeira vez a aparência da casa, tem a sensação de estar em um lugar que não condiz com a realidade, pois a casa parecia ter vida própria:

Tabela 1: trechos de psicose, de Robert Bloch, e suas traduções T1 e T2

\begin{tabular}{|c|c|c|}
\hline Psycho - Robert B & $\begin{array}{l}\text { Psicose - tradução de Olívia } \\
\text { Krähenbühl, } 1961\end{array}$ & $\begin{array}{l}\text { Psicose - tradução de Anabela } \\
\text { Paiva, } 2013\end{array}$ \\
\hline $\begin{array}{l}\text { Lila went up the steps, reaching } \\
\text { the porch just before the rain } \\
\text { came. } \\
\text { The house was old, its frame } \\
\text { siding gray and ugly here in the } \\
\text { half-light of the coming storm. } \\
\text { Porch boards creaked under her } \\
\text { feet, and she could hear the } \\
\text { wind rattling the casements of } \\
\text { the upstairs windows. [...] } \\
\text { Lila knocked again, and the } \\
\text { house groaned a hollow echo. } \\
\text { The sound of the rain drowned } \\
\text { it out, and she didn't bother to } \\
\text { listen closely (BLOCH, 2010, p. } \\
\text { 153, grifos nossos). }\end{array}$ & $\begin{array}{l}\text { LILA subiu os degraus e bateu à } \\
\text { porta antes que a chuva } \\
\text { desabasse. } \\
\text { A casa era velha, a madeira de } \\
\text { que era feita tão feia quanto } \\
\text { encardida à meia-luz da } \\
\text { tormenta que se aproximava. O } \\
\text { soalho do alpendre rangia sob } \\
\text { seus pés, e ela podia ouvir o } \\
\text { vento chocalhando as janelas do } \\
\text { primeiro andar. [...] } \\
\text { Bateu de novo e a casa soltou } \\
\text { um gemido cavernoso. O ruído } \\
\text { da chuva abafou-o, e ela não se } \\
\text { deu o trabalho de aplicar um } \\
\text { ouvido mais atento (BLOCH, } \\
\text { 1961, p. 85, grifos nossos). }\end{array}$ & $\begin{array}{l}\text { Lila subiu os degraus e chegou à } \\
\text { varanda bem na hora em que a } \\
\text { chuva desabou. } \\
\text { A casa era velha e sua estrutura } \\
\text { de madeira era gasta e cinzenta } \\
\text { à meia-luz da tormenta que se } \\
\text { aproximava. O assoalho da } \\
\text { varanda rangia sob seus pés e } \\
\text { ela podia ouvir o vento } \\
\text { chacoalhando os caixilhos das } \\
\text { janelas do primeiro andar. [...] } \\
\text { Lila bateu de novo, e a casa } \\
\text { gemeu um eco cavernoso, o som } \\
\text { da chuva abafou. Ela não se deu } \\
\text { ao trabalho de tentar ouvir } \\
\text { melhor (BLOCH, 2013, p. 209, } \\
\text { grifos nossos). }\end{array}$ \\
\hline
\end{tabular}

No que diz respeito ao nível lexical, nota-se que T1 e T2 optaram por escolhas diferentes, posto que T1 traduziu "The house was old, its frame siding gray and ugly here 


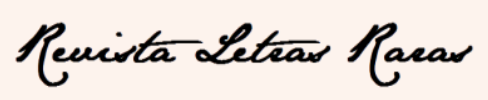

ISSN: 2317-2347 - v. 7, Edição Especial (2018).

in the half-light of the coming storm." como "A casa era velha, a madeira de que era feita tão feia quanto encardida à meia-luz da tormenta que se aproximava.”, ao passo que T2 optou por "A casa era velha e sua estrutura de madeira era gasta e cinzenta à meia-luz da tormenta que se aproximava.". Nesse sentido, observa-se que T1 traduziu "gray" como "encardida", que também pode significar "cinzenta". Tal escolha, muito possivelmente, está ligada ao vocabulário da época em que o P2 está inserido, e isso também cabe para a $\mathrm{T} 2$ e seu respectivo polissistema.

Sendo assim, com base nessa primeira descrição da aparência externa da casa de Norman Bates, pode-se constatar que ambas traduções com suas peculiaridades, obviamente, constroem uma ambientação que as conduz para um espaço sombrio e misterioso, o qual, mais adiante, vai aterrorizar a personagem Lila. Dessa forma, ainda dentro do micronível, as cenas que melhor descrevem a casa dos Bates estão sob o ponto de vista de Lila, que após o desaparecimento de Mary decide procurá-la chegando, assim, até Norman Bates. Logo na entrada da casa, a aparência e decoração antigas perturbam Lila que, em decorrência disso, sente um clima muito estranho no ambiente:

Tabela 2: trechos de psicose, de Robert Bloch, e suas traduções T1 e T2

\begin{tabular}{|c|c|c|}
\hline$-\mathbf{R o}$ & $\begin{array}{l}\text { Psicose - tradução de Olívia } \\
\text { Krähenbühl, } 1961\end{array}$ & $\begin{array}{l}2013 \\
\text { - tradução de Anabela }\end{array}$ \\
\hline $\begin{array}{l}\text { Lila stood in the hall. It was } \\
\text { darker inside the house than out } \\
\text { there on the porch. But there } \\
\text { must be a light switch } \\
\text { somewhere along the wall here. } \\
\text { She found it, snapped it on. The } \\
\text { unshaded overhead bulb gave } \\
\text { off a feeble, sickly glare against } \\
\text { the background of peeling, } \\
\text { shredded wallpaper. What was } \\
\text { the design--bunches of grapes, } \\
\text { or were they violets? Hideous. } \\
\text { Like something out of the last } \\
\text { century. A glance into the parlor } \\
\text { confirmed the observation. Lila } \\
\text { didn't bother to go in. The } \\
\text { rooms on this floor could wait } \\
\text { until later. Arbogast had said he } \\
\text { saw someone looking out of a } \\
\text { window upstairs. That would be } \\
\text { the place to begin. } \\
\text { There was no light switch for } \\
\text { the stairway. Lila went up } \\
\text { slowly, groping along the } \\
\text { banister. As she reached the }\end{array}$ & $\begin{array}{l}\text { Entrou no vestíbulo. Estava } \\
\text { mais escuro do que lá fora. Mas } \\
\text { teria que haver um interruptor } \\
\text { ao longo da parede... } \\
\text { Encontrou-o. Acendeu a luz. A } \\
\text { lâmpada, sem o abajur, no teto, } \\
\text { dava uma débil claridade } \\
\text { doentia contra um fundo de } \\
\text { papel de parede descascado, } \\
\text { caindo aos pedaços. } \\
\text { Que figuras eram aquelas? } \\
\text { Cachos de uvas ou violetas? } \\
\text { Pavorosas. Coisas do século } \\
\text { passado. } \\
\text { Um olhar relanceado pela sala } \\
\text { confirmou-lhe a observação. } \\
\text { Lila não queria entrar ali. As } \\
\text { salas do andar térreo podiam } \\
\text { ficar para mais tarde. Arbogast } \\
\text { dissera ter visto alguém } \\
\text { espiando de uma janela no } \\
\text { andar superior. Era por ali que } \\
\text { devia começar. } \\
\text { Na escada não havia interruptor. } \\
\text { Subiu devagar, tateando o }\end{array}$ & $\begin{array}{l}\text { Lila entrou no vestíbulo. Estava } \\
\text { mais escuro do que a varanda. } \\
\text { Mas deveria haver um } \\
\text { interruptor em algum lugar ao } \\
\text { longo da parede. } \\
\text { Ela o encontrou e acendeu a luz. } \\
\text { A lâmpada do teto, sem } \\
\text { luminária, dava uma claridade } \\
\text { débil, doentia, contra o fundo de } \\
\text { papel de parede descascado. O } \\
\text { que eram aqueles desenhos - } \\
\text { cachos de uvas, violetas? } \\
\text { Pavorosos. Coisas do século } \\
\text { passado. } \\
\text { Um olhar de relance na sala } \\
\text { confirmou a impressão. Lila não } \\
\text { quis entrar. As salas do andar } \\
\text { térreo poderiam ficar para mais } \\
\text { tarde. Arbogast tinha dito que } \\
\text { vira alguém espiando de uma } \\
\text { janela no andar de cima. Era por } \\
\text { lá que deveria começar. } \\
\text { Na escada não havia interruptor. } \\
\text { Subiu devagar, tateando o } \\
\text { corrimão, ao chegar ao patamar, }\end{array}$ \\
\hline
\end{tabular}




\section{Revista Leteas Racar}

ISSN: 2317-2347 - v. 7, Edição Especial (2018).

landing, the thunder came. The whole house seemed to shake with it. Lila gave an involuntary shudder, then relaxed. It was involuntary, she told herself. Perfectly natural. Certainly, there was nothing about an empty house like this to frighten anybody (BLOCH, 2010, p. 155, grifos nossos). corrimão. Ao chegar ao patamar, o trovão estrondou. A casa inteira pareceu cambalear. Ela vibrou num tremor involuntário, mas retomou a calma. Foi "sem querer" desculpou-se perante si mesma. Perfeitamente natural. Nada havia naquela casa deserta capaz de assustar quem quer que fôsse (BLOCH, 1961, p. 86, grifos nossos). o trovão estrondou. A casa inteira pareceu chacoalhar. Lila sentiu um tremor involuntário, depois relaxou. Foi sem querer, disse a si mesma. Perfeitamente natural. Certamente, não havia nada capaz de assustar alguém naquela casa vazia (BLOCH, 2013, p. 211, grifos nossos).

O micronível das duas traduções acima é distinto, uma vez que T1 omite o nome de "Lila" em algumas frases ou troca pelo pronome "ela" em outras. Já a T2 se preocupa em manter um discurso mais direto e coloquial, enquanto a T1 se preocupa em usar ênclises em vários momentos ("encontrou-o", “desculpou-se”), além de expressões mais eruditas ("retomar a calma"), a fim de passar um discurso mais formal, o que difere um pouco da proposta de Bloch.

Com efeito, o excerto apresentado na Tab. 2 demonstra a preocupação do narrador em descrever o espaço e a ambientação muito minuciosamente, tanto que o suspense vai aumentando na medida em que o texto é lido com a ajuda, evidentemente, das frases curtas, as quais foram mantidas nas duas traduções. A escolha da ambientação noturna, com trovões e muita escuridão, também corrobora muito para a construção desse espaço de horror, pois, conforme aponta Ceserani, “A ambientação preferida pelo fantástico é aquela que remete ao mundo noturno." (2006, p. 77).

De fato, o ponto culminante do horror na narrativa não é o momento em que Mary foi morta com várias facadas, mas sim quando Lila encontra o porão da casa de Norman:

Tabela 3: trechos de psicose, de Robert Bloch, e suas traduções T1 e T2

\begin{tabular}{|c|c|c|}
\hline Psycho-Ro & $\begin{array}{l}\text { Psicose - tradução de Olívia } \\
\text { Krähenbühl, } 1961\end{array}$ & $\begin{array}{l}\text { Psicose - tradução de Anabela } \\
\text { Paiva, } 2013\end{array}$ \\
\hline $\begin{array}{l}\text { The basement stairs were just } \\
\text { ahead. She fumbled at the wall } \\
\text { until her hand brushed over } \\
\text { another switch. The light went } \\
\text { on below, just a faint and } \\
\text { faltering glow in the darkened } \\
\text { depths. Thunder growled in } \\
\text { counterpoint to the clatter of her } \\
\text { heels. } \\
\text { The, bare bulb dangled from a } \\
\text { cord directly in front of the } \\
\text { furnace. It was a big furnace, }\end{array}$ & $\begin{array}{l}\text { A escada do porão estava à sua } \\
\text { frente. Tateou a parede em } \\
\text { busca de outro interruptor. A luz } \\
\text { se acendeu em baixo, apenas um } \\
\text { clarão enfraquecido na } \\
\text { profundeza tenebrosa. O trovão } \\
\text { roncava, contraponteando o } \\
\text { castanholar de seus saltos. } \\
\text { A lâmpada nua se balançava de } \\
\text { um fio bem na frente da } \\
\text { fornalha. Era uma fornalha } \\
\text { grande, com uma porta de ferro, }\end{array}$ & $\begin{array}{l}\text { A escada do porão estava bem à } \\
\text { frente. Tateou a parede até que } \\
\text { sua mão encontrou outro } \\
\text { interruptor. A luz se acendeu lá } \\
\text { embaixo, apenas um clarão } \\
\text { fraco e vacilante nas } \\
\text { profundezas do escuro. O trovão } \\
\text { roncava, em contraponto às } \\
\text { batidas dos seus saltos. } \\
\text { A lâmpada se balançava por um } \\
\text { fio bem em frente à caldeira. } \\
\text { Era uma caldeira grande, com }\end{array}$ \\
\hline
\end{tabular}




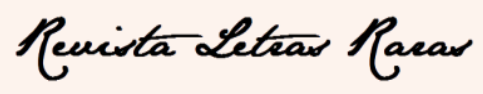

ISSN: 2317-2347 - v. 7, Edição Especial (2018).

with a heavy iron door. Lila stood there, staring at it. She was trembling now, she admitted that to herself; [...] The door. The blanket had concealed it completely, but there must be another room here, probably an old-fashioned fruit cellar. That would be the ideal place to hide and wait. [...] Lila opened the door of the fruit cellar.

It was then that she screamed.

She screamed when she saw the old woman lying there, the gaunt, gray-haired old woman whose brown, wrinkled face grinned up at her in an obscene greeting.

"Mrs. Bates!" Lila gasped.

"Yes."

But the voice wasn't coming from those sunken, leathery jaws. It came from behind her, from the top of the cellar stairs, where the figure stood

(BLOCH, 2010, p. 161-163, grifos do autor e nossos). uma porta de ferro, pesada. Lila parou ali, olhando para ela. Estrava tremendo, admitia agora para si mesma; $[. .$.

A porta. A manta tapava completamente, mas deveria haver um quarto por trás dela, provavelmente um daqueles antigos depósitos de frutas. Aquele seria o lugar ideal para alguém se esconder e esperar. [...]

Lila abriu a porta do depósito de frutas.

Foi aí que gritou.

Gritou ao ver a velha deitada ali, uma velha emaciada, de cabelos brancos, com o rosto enrugado e escuro, arregrava os dentes para ela, num sorriso obsceno.

'Senhora Bates!', gritou Lila.

'Sim'.

Mas a voz não estava saindo das mandíbulas fundas, endurecidas. Veio de algum lugar por trás dela [...] (BLOCH, 2013, p. 217-219, grifos do autor e nossos).

Neste último trecho, percebe-se que a T1 deu ênfase em itálico para a palavra "castanholar", a qual não está grifada na versão de Bloch e nem na T2. Além disso, a T1 também omite uma parte do texto, "probably an old-fashioned fruit cellar", ao passo que a T2 decide manter essa frase, pois aumenta a ambientação insólita que o texto de Bloch sugere. Nessa perspectiva, também é notável a forma com que o narrador, ao descrever o espaço, cria uma ambientação narrativa com um clima de horror, sugerindo, muitas vezes, a presença do insólito, conforme foi apontado acima.

Por fim, a respeito do "Contexto sistêmico", pode ser tomado como base os conceitos de "procedimentos estrangeirizadores" e "procedimentos domesticadores", postulados de Lanzetti et al. (2009):

Os procedimentos estrangeirizadores aproximam o texto de chegada do texto original através do recurso de manutenção de itens lexicais, estruturas e estilo. Os procedimentos domesticadores afastam o texto de chegada do texto original, aproximando a tradução das estruturas linguísticas e da realidade extratextual da língua e da sociedade-alvo (LANZETTI et al., 2009, p. 3). 


\section{Revista Leteas Racar}

ISSN: 2317-2347 - v. 7, Edição Especial (2018).

Sendo assim, analisando-se o eixo domesticação-estrangeirização, conjectura-se que a T1 apresente predominância de estratégias domesticadoras, haja vista que aparenta aproximar o texto partida ao contexto brasileiro de sua época, deixando algumas marcas do texto fonte de lado, conforme pode ser observado nas expressões grifadas nas tabelas acima. Vale ressaltar que essa estratégia se deve ao fato de que Krähenbühl valoriza uma tradução literária e, para isso, levou em consideração parâmetros literários utilizados em sua cultura de chegada.

Não obstante, a T2 pode ser entendida como uma tradução que utiliza procedimentos estrangeirizadores, dado que procura manter a mesma estrutura e marcas do texto de partida no texto de chegada. Aliás, a proposta da tradutora Anabela Paiva era justamente essa, aproximar sua tradução ao texto fonte, além de "buscar ao máximo reproduzir a agilidade e coloquialidade do texto de Bloch, a economia do seu estilo, a sua capacidade de nos transportar para as cenas, com descrições vívidas e emocionantes." (PAIVA, 2017, s/p).

\section{Considerações finais}

Em suma, este breve estudo de duas traduções da obra Psicose (1959), de Robert Bloch, a primeira traduzida por Olívia Krähenbühl em 1961 e a segunda por Anabela Paiva em 2013, primeiramente, contextualizou o autor Robert Bloch e sua poética, uma vez que o escritor e roteirista estadunidense, apesar de muito profícuo, é pouco conhecido no Brasil. Também, observou-se que, a partir do polissistema em que estava inserido, o discípulo mais jovem de H. P. Lovecraft criou Norman Bates baseado na história de um dos maiores psicopatas estadunidenses, Ed Gein. Contudo, mais do que um romance de suspense, Bloch criou em Psicose uma ambientação insólita, característica da Literatura Fantástica e clara influência de seu mestre, gerado através de suas escolhas lexicais e da forma com que o foco narrativo age na trama.

Nesse sentido, a tradução de Krähenbühl (1961) chegou ao Brasil em um contexto em que havia um certo vácuo literário das produções brasileiras, bem como a tradução de Paiva (2013). Entretanto, mesmo sendo dois trabalhos de tradução da mesma obra literária e para o mesmo código linguístico, verificou-se, a partir de uma concisa análise 


\section{Revista Leteas Racar}

ISSN: 2317-2347 - v. 7, Edição Especial (2018).

do macronível e do micronível, que as duas traduções possuem suas peculiaridades, posto que seus respectivos polissistemas estão inseridos em contextos bem diferentes.

Assim, foi possível dizer que a tradução de Krähenbühl (1961) é uma tradução com tendências de predominância domesticadora, posto que optou por traduzir o texto de acordo com as convenções do contexto do Brasil dos anos 60 do século XX. Além disso, verificam-se marcas da escritora/tradutora por meio da adoção de frases curtas e construção gradual do suspense, transpondo um estilo próprio, que ela mesma defende em seu artigo incluído nesta pesquisa.

A tradução de Paiva (2013), por outro lado, aponta uma preponderância estrangeirizante, pois que opta por aproximar-se das estruturas e marcas do texto de Bloch, apesar de ser escrita no século XXI. Nessa perspectiva, notou-se também que, ressalvado seus contextos de produção, ambas traduções constroem espaço e ambientação insólitos, aos modos da obra de Bloch e das recomendações de Poe e Lovecraft.

Por fim, é importante destacar a relevância de Psicose (1959) na atualidade do polissistema cultural e literário brasileiro, posto que a série Bates Motel (2017), inspirada no romance de Bloch, estimulou a nova tradução de Psicose no século XXI. Nesse sentido, também destaca-se que com esse artigo não se pode generalizar a respeito dos trabalhos tradutórios realizados, entretanto, constitui um estudo piloto que oferece potencial de descrever algumas marcas do espaço e ambientação insólita nas traduções realizadas.

\section{REFERÊNCIAS}

BLOCH, Robert. Psycho. New York: The Overllok Press, 2010. Psicose. Tradução Olívia Krähenbühl. São Paulo: Best Seller, 1961.

Books, 2013. Psicose - Limited Edition. Tradução Anabela Paiva. Rio de Janeiro: DarkSide Psicose - Classic Edition. Tradução Anabela Paiva. Rio de Janeiro: DarkSide Books, 2013.

BRANDÃO, Liv. 'Psicose', o livro que fisgou Hitchcock, é relançado no Brasil. O Globo, Rio de Janeiro, 14 ago. 2013. Disponível em: <https://oglobo.globo.com/cultura/psicoselivro-que-fisgou-hitchcock-relancado-no-brasil-9511396\#ixzz52x1LSqMT>. Acesso em: 01 dez. 2017. 


\section{Reuista Letear Racar}

ISSN: 2317-2347 - v. 7, Edição Especial (2018).

CESERANI, Remo. O Fantástico. Tradução Nilton Cezar Tridapalli. Curitiba: Ed. UFPR, 2006.

COSOY, Ilana. Serial killers: louco ou cruel? Rio de Janeiro: DarkSide Books, 2014.

DARKSIDE. Psicose. Disponível em: <http://www.darksidebooks.com.br/psicose/>. Acesso em: 05 out. 2017.

EVEN-ZOHAR, Itamar. Teoria dos Polissistemas. Tradução Luis Fernando Marozo; Carlos Rizzon; Yanna Karlla Cunha. Revista Translatio, n. 5. Porto Alegre, 2013. Disponível em: <http://www.seer.ufrgs.br/translatio/article/viewFile/42899/27134>. Acesso em: 05 out. 2017.

KRÄHENBÜHL, Olívia. Duplo aspecto da tradução. Correio da manhã, Rio de Janeiro, 3 set. 1944, página 1 e 4.4 Disponível em: $<$ http://memoria.bn.br/DocReader/DocReader.aspx ?bib=089842_05\&PagFis=22330\&Pes q=>. Acesso em: 28 nov. 2017.

LAMBERT, José. Sobre a descrição de traduções. Tradução Marie-Hélène Catherine Torres; Lincoln P. Fernandes. In: Literatura \& tradução: textos selecionados de José Lambert. GUERINI, A.; TORRES, M.H. C.; COSTA, W. (orgs.). Rio de Janeiro: 7Letras, 2011.

em: <https://repositorio.ufsc.br/bitstream/handle/123456789/178897/Jose\%20Lambert\%20Lit eratura \%20e\%20traducao\%202011.pdf?sequence=1\&isAllowed=y $>$. Acesso em: $02 \mathrm{dez}$. 2017.

LANZETTI, Rafael et al. Procedimentos Técnicos de Tradução - Uma proposta de reformulação. Revista do ISAT, n. 7. São Gonçalo-RJ, 2009. Disponível em: $<$ https://pt.scribd.com/document/185400020/Procedimentos-tecnicos-de-traducao>.

Acesso em: $02 \mathrm{dez} .2017$

LEFEVERE, André. Tradução, reescrita e manipulação da fama literária. Tradução: Claudia Matos Seligmann. Bauru, SP: EDUSC, 2007.

LOVECRAFT, Howard Phillips. O horror sobrenatural em literatura. Tradução Celso M. Paciornik. São Paulo: Iluminuras, 2007.

PAIVA, Anabela. Entrevista com Anabela Paiva, tradutora de Psicose, de Robert Bloch. [dezembro, 2017] Entrevista concedida a Carla Helena Lange.

POE, Edgar Allan. A filosofia da composição. In: Medo clássico: Edgar Allan Poe: coletânea inédita de contos do autor. Tradução Marcia Heloisa Amarante Gonçalves. Rio de Janeiro: DarkSide Books, 2017.

REBELLO, Stephen. Alfred Hitchcock e os bastidores de Psicose. Tradução Rogério Durst. Rio de Janeiro: Intrínseca, 2013.

TOURY, Gideon. Descriptive Translation Studies and Beyond. Revised Edition. Philadelphia: John Benjamin Publishings, 2012. 


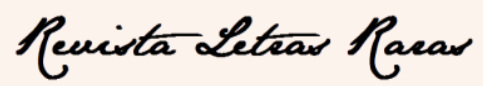

ISSN: 2317-2347 - v. 7, Edição Especial (2018).

\begin{abstract}
APÊNDICE A
ENTREVISTA COM ANABELA PAIVA, TRADUTORA DE PSICOSE, DE ROBERT BLOCH.
\end{abstract}

\title{
1. Poderia fazer uma breve explicação sobre a sua formação acadêmica e experiência/trajetória profissional, principalmente com relação aos trabalhos com tradução.
}

Anabela Paiva: Infelizmente, até agora, a tradução de Psicose foi a única que fiz. Sou jornalista formada pela Universidade Federal Fluminense (UFF) e trabalho basicamente como consultora de comunicação e editora. Vivi de 1989 a 1992 nos Estados Unidos (Washington D.C. e Cambridge, MA), onde atuei como correspondente da Veja e Jornal do Brasil, entre outros veículos, e passei uma temporada em Harvard. Desde então me mantenho em contato com a língua inglesa. Trabalhei como repórter e editora em grandes veículos (Isto É, Época, Jornal do Brasil, www.no.com) e criei o site de notícias sobre o Rio de Janeiro Vozerio. Desde 2004, também desenvolvo pesquisas sobre a mídia, como pesquisadora associada do Centro de Estudos de Segurança e Cidadania. Sou co-autora dos livros "Mídia e Violência: Novas Tendências na Cobertura de Segurança e Criminalidade", com Silvia Ramos, e "A dona das Chaves: Uma mulher no comando das prisões do Rio de Janeiro", com Julita Lemgruber.

2. Além das traduções, você já produziu algum outro livro ou produção literária? 


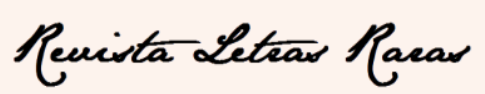

ISSN: 2317-2347 - v. 7, Edição Especial (2018).

A.P.: Os citados acima. O primeiro é uma investigação sobre a qualidade da cobertura de segurança pública produzida pela imprensa, com base na análise de milhares de matérias e em 90 entrevistas com jornalistas e especialistas e vários artigos de convidados. O segundo tem cunho biográfico e escrevi a quatro mãos com a socióloga Julita Lemgruber.

\section{Como você vê o trabalho do tradutor frente às obras literárias?}

A.P.: O trabalho do tradutor, sem dúvida, é quase o de um co-autor da obra, especialmente em gêneros como a poesia. Quem traduz precisa encarar o trabalho com uma mistura de coragem e cuidado. Coragem, para, se necessário, fazer escolhas estilísticas de modo que o resultado da tradução seja fiel ao estilo e às intenções do original, e não apenas uma tradução literal. Ao mesmo tempo, cautela, para jamais ultrapassar este simples objetivo - o que seria trair a obra literária.

\section{Qual a sua visão sobre a falta de reconhecimento e a invisibilidade que muitos tradutores ainda têm frente às suas produções?}

A.P.: O mercado editorial no Brasil tem crescido e se sofisticado e, parece-me, os tradutores vem ganhando maior destaque. A literatura russa, por exemplo, ganhou novas traduções do original nos últimos anos, e isso foi saudado pela imprensa. Vem-me também à memória a tradução de "Mil e Uma Noites", por Mamede Mustafa Jarouche, muito celebrada. Mas, de fato, são casos isolados - em geral, a tradução só chama a atenção quando é ruim! Pelo menos a Biblioteca Nacional abriu um edital de apoio à tradução recentemente, o que não deixa de ser uma forma de valorizar a atividade.

\section{O que lhe motivou a traduzir Psicose, de Robert Bloch? Você já conhecia o autor e essa obra ou teve só teve contato a partir do filme homônimo de Hitchcock? Foi necessário fazer alguma pesquisa antes de iniciar a tradução?}

A.P.: Fui convidada pelo Christiano Menezes, diretor editorial da DarkSide, que se empenhou muito para localizar os detentores dos direitos e relançar o livro, que estava esgotado há décadas no Brasil. Eu só conhecia o filme e não tinha contato com o livro. 


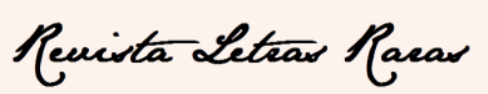

ISSN: 2317-2347 - v. 7, Edição Especial (2018).

Antes de começar, naturalmente li o que pude sobre Bloch, a influência de Lovecraft na sua carreira, sua atuação como autor de roteiros. Um autor prolífico e premiado, que fez muito mais do que seu livro mais famoso. Mas meu trabalho se concentrou em Psicose.

\section{A editora fez alguma exigência para a sua tradução ou alguma "correção"? Se a resposta for afirmativa, você sabe por qual motivo?}

A.P.: Creio que não houve qualquer mudança além da revisão.

\section{Poderia explicar se há um projeto tradutório para essa obra? Quais foram as suas escolhas/objetivos tradutórios? Quais foram os maiores desafios e dificuldades no processo tradutório?}

A.P.: Desde o início, meu objetivo foi tornar o texto em português o mais próximo possível do original. Isso exigiu praticamente fazer uma nova tradução.

Você pode ver a tradução da edição de 1960 aqui.

https://www.scribd.com/document/358011151/Psicose-Robert-Bloch-pdf

Quando comparei a tradução da edição dos anos 60 com o original de Bloch, levei um susto. $\mathrm{O}$ texto em inglês tinha muito mais força, densidade. $\mathrm{E}$ era bem mais direto e objetivo. A narração usa frases e palavras curtas, expressões coloquiais, gírias todo o tempo. Além disso, busca reproduzir a própria modulação da fala, ao colocar em itálico palavras que, ditas em voz alta pelo personagem, teriam mais ênfase. Exemplos: "God, could she read his mind?" (capítulo 1); "In fact, whem you came right down to it, some people don't seem to get any oportunities at all." (capítulo 2).

Esse recurso é fundamental para tornar mais vivo e emocionante o diálogo interno dos personagens, que na verdade é a grande força da obra. Todo o tempo, acompanhamos Norman Bates em permanente diálogo consigo mesmo, comentando o que lhe diz a Mãe e outros personagens. Busquei reproduzir fielmente essa entonação na versão em português. Ao mesmo tempo, retirei alguns itálicos que não estavam no original. Por exemplo, logo na segunda página, quando Norman lê o livro sobre a civilização inca. Na tradução antiga, lê-se “... a descrição da cachua, por exemplo, onde os guerreiros formavam um vasto círculo que se movia e contorcia como uma cobra enorme." 


\section{Reuista Leteas Paear}

ISSN: 2317-2347 - v. 7, Edição Especial (2018).

No original: "For example, this description of the cachua, or victory dance, where the warriors formed a great circle, moving and writhing like a snake."

$\mathrm{Na}$ tradução antiga, o texto ganhou construções muito formais e inversões que não usamos cotidianamente ("tal riqueza", "amplo colo"). Talvez em respeito aos usos da época, o tradutor usava ênclises (“deixo-o”) e palavras pouco coloquiais ("bátega", algaravia). Na nova tradução, procurei usar a ordem direta, o vocabulário cotidiano, as frases e parágrafos curtos.

Também reproduzi a forma com que o personagem da Mãe era denominado no original, nos trechos em que acompanhamos o pensamento de Norman. Sempre com maiúsculas, sem artigos, pronomes. Mother é o nome dessa mãe monstruosa. Como na frase: "Drive away from the motel, away from Mother, away from that thing lying under the rug in the hall?”. Essa particularidade não estava na tradução antiga.

Esse foi, portanto, o grande desafio da obra: buscar ao máximo reproduzir a agilidade e coloquialidade do texto de Bloch, a economia do seu estilo, a sua capacidade de nos transportar para as cenas, com descrições vívidas e emocionantes.

\section{Você utilizou algum software/material de apoio (exemplo: dicionário técnico) para fazer essa tradução ou fez a mão/direto no computador?}

A.P.: Não usei nenhum material especial. Apenas dicionários comuns, como o Oxford. E muita pesquisa na internet também, para entender o sentido de algumas expressões.

Data de recebimento: $31 / 05 / 2018$

Data de aceite: $25 / 11 / 2018$ 